\title{
Avaliação fisiológica e comportamental de cães utilizados em terapia assistida por animais (TAA)
}

[Phyisiological and behavioral assessment in dogs used in Animal-Assisted Therapy (AAT)]

\author{
K.C.M. Yamamoto ${ }^{1}$, E.Y.T. Silva ${ }^{2}$, K.N. Costa ${ }^{1}$, M.S. Souza ${ }^{1}$, M.L.M. Silva ${ }^{2}$, V.B. Albuquerque ${ }^{3}$, \\ D.M. Pinheiro ${ }^{4}$, D.G. Bernabé ${ }^{5}$, V.N.L.S. Oliva ${ }^{6}$ \\ ${ }^{1}$ Médica veterinária autônoma \\ ${ }^{2}$ Aluno de graduação - Faculdade de Medicina Veterinária de Araçatuba - FMVA-UNESP, Araçatuba, SP \\ ${ }^{3}$ Aluna de pós-graduação - Faculdade de Medicina de Botucatu -FMB-UNESP - Botucatu, SP \\ ${ }^{4}$ Técnica de Laboratório - Faculdade de Medicina Veterinária de Araçatuba -FMVA-UNESP, Araçatuba, SP \\ ${ }^{5}$ Aluno de pós-graduação - Faculdade de Odontologia de Araçatuba - FOA-UNESP, Araçatuba, SP \\ ${ }^{6}$ Faculdade de Medicina Veterinária de Araçatuba - FMVA-UNESP - Araçatuba, SP
}

\begin{abstract}
RESUMO
Realizou-se a observação comportamental de nove cães terapeutas (oito da raça Labrador Retriever e um Golden Retriever), dosaram-se cortisol sérico e salivar, aferiram-se a temperatura retal, a pressão arterial sistólica e as frequências cardíaca e respiratória nos seguintes momentos: M0 (média de três avaliações do cão em repouso) e em M1, M2 e M3 (imediatamente antes, imediatamente após e decorridas 24h das atividades de terapia assistida por animais - TAA), respectivamente. Não houve diferença significativa quanto às características estudadas $(\mathrm{P}>0,05)$, exceto pela temperatura, que foi mais elevada em M1 e M2 do que em M0 (P=0,009). A avaliação comportamental, realizada de maneira descritiva, não apresentou alteração negativa. Houve diferença significativa quanto à concentração de cortisol sérico entre os momentos M1 e M3 ( $\mathrm{P}=0,071)$, e não ocorreu diferença da concentração do cortisol salivar entre os quatro momentos $(\mathrm{P}=0,746)$. As alterações observadas foram atribuídas à contenção e à manipulação dos animais e não desencadearam desconforto físico ou estresse dignos de nota em cães.
\end{abstract}

Palavras-chave: cão, comportamento, cortisol, parâmetros vitais, terapeutas

\begin{abstract}
Behavioral observation of nine therapist dogs (eight Labrador Retrievers and one Golden Retriever) was performed and serum and salivar cortisol dosage, rectal temperature, systolic blood pressure and heart and respiratory rates were measured and evaluated at the following moments: MO (average of three evaluations of the dog at rest) and M1, M2 e M3 (immediately before, at the end and 24 hours after the AAT activities, respectively). There was no significant difference in the parameters between the moments $(P>0.05)$ except for temperature, which was higher in M1 and M2 than MO $(P=0.009)$. The behavioral assessment was conducted in a descriptive way and didn't present a negative effect. There was significant difference when comparing the serum cortisol levels between M1 and M3 (P=0.0712). There wasn't asignificant difference in salivary cortisol levels when comparing the values of the four moments $(P=0.7458)$. The observed alterations are probably related to the containment and handling of animals, demonstrating that the therapy doesn't have a negative effect on dogs.
\end{abstract}

Keywords: dog, behavior, cortisol, vital parameters, therapists

Recebido em 25 de maio de 2011

Aceito em 6 de março de 2012

E-mail: karinacristiany@hotmail.com 


\section{INTRODUÇÃO}

A terapia assistida por animais (TAA) consiste na utilização de animais como instrumentos facilitadores de abordagem e de estabelecimento de terapias de pacientes, tais como aqueles com necessidades especiais, crianças com distúrbios cognitivos ou emocionais e idosos. O termo tem sido recomendado pela Delta Society (www.deltasociety.org), para definir as terapias nas quais o animal é utilizado como motivador, em substituição a outras terminologias menos específicas, como pet-terapia ou zooterapia (Dotti, 2005; Oliva, 2010). Reconhecida em diversos países do mundo, essa terapia é comprovadamente uma técnica útil na socialização de pessoas, na psicoterapia, em tratamentos de pacientes com necessidades especiais e na diminuição da ansiedade de várias causas. Essa abordagem terapêutica em pacientes idosos e com necessidades especiais também fornece auxílio terapêutico a pacientes com doenças graves (Oliva, 2007). Tal atividade baseia-se no uso de animais chamados coterapeutas, os quais devem apresentar boa saúde física e mental visando ao bem-estar do animal e à segurança do paciente assistido quanto a riscos de zoonoses e comportamentos inadequados (Oliva, 2007).

Os cães são os animais mais apropriados para o uso em atividades terapêuticas por terem adquirido comportamento semelhante ao do homem ao sofrerem as mesmas pressões seletivas (Udell e Wynne, 2008).

Muitos trabalhos relatam os benefícios que os cães proporcionam aos pacientes humanos, porém poucos demonstram os efeitos dessa atividade sobre os cães utilizados na TAA (Haubenhofer e Kirchengast, 2006). A avaliação do bem-estar ou do estresse excessivo não é fácil e alguns métodos de análise são bastante subjetivos. Dentre as formas de avaliação mais objetivas, encontram-se a dosagem do cortisol e a mensuração de variações significativas de características fisiológicas, especialmente a pressão arterial.

O uso de técnicas não invasivas pode ser considerado a melhor opção para se obter amostras de saliva, urina e fezes, que serão analisadas com o intuito de avaliar o estresse por meio da variação das concentrações hormonais. Alguns autores sugerem que esse tipo de colheita não expõe o animal a qualquer estresse adicional, o qual influenciaria nos resultados (Beerda et al., 1996; Queyras e Carosi, 2004). Vários trabalhos afirmam que a dosagem de cortisol em amostras de saliva é um método efetivo de mensuração dos estresses agudo (Beerda et al., 1998) e crônico (Beerda et al., 1999), sendo esta proporcional à concentração sérica com elevação após cerca de quatro minutos decorridos do aumento do cortisol sérico (Kobelt et al., 2003).

Há relatos de que a TAA eleve a concentração de cortisol, tanto pelo próprio trabalho terapêutico quanto pelas circunstâncias às quais o animal é submetido, entre elas: ambiente novo, contato com pessoas desconhecidas e transporte, que podem causar ansiedade (Haubenhofer e Kirchengast, 2006). Dessa maneira, torna-se bastante relevante o conhecimento do real grau de estresse que as atividades de TAA possam vir a desencadear nos cães, pois a ansiedade sofrida pelo animal pode induzir a situações de perigo, sejam elas reais ou imaginárias (Frank et al., 2006). Frente à importância do tema para a saúde do animal e do paciente assistido e à controvérsia existente entre os autores a respeito do tema, o desenvolvimento de mais pesquisas nesta área são perfeitamente justificadas.

Portanto, este trabalho teve como objetivo analisar os efeitos da TAA nos cães terapeutas na hipótese de que tal atividade possa desencadear estresse, utilizando-se como meios a mensuração dos valores de cortisol sérico e salivar, as variações paramétricas e a observação de alterações de comportamento.

\section{MATERIAL E MÉTODOS}

Foram incluídos neste estudo nove cães terapeutas, sendo oito Retriever do Labrador e um Golden Retriever. Todos os cães fazem parte do projeto de extensão Cão-Cidadão-Unesp, que utiliza cães como facilitadores do atendimento de idosos e de pacientes especiais, em três diferentes instituições da cidade de Araçatuba, SP. Tais cães estão inseridos na equipe executora do projeto há mais de um ano, em atividade ininterrupta, estando totalmente adaptados às atividades de TAA e realizando uma visita semanal de duração de 60 minutos, em cada instituição. 
Estudaram-se as dosagens de cortisol sérico e salivar, a avaliação paramétrica e a observação de alterações comportamentais, em determinados momentos. Primeiramente foram aferidas as características vitais dos animais, como: frequências cardíaca e respiratória, pressão arterial e temperatura, nesta ordem, seguindo-se a coleta de sangue e de saliva.

Foram considerados quatro momentos: momento zero (M0): média de três avaliações realizadas em três diferentes dias, nos quais os animais estavam no ambiente domiciliar e não desenvolviam as atividades de terapia; momento 1 (M1): avaliado imediatamente antes do início das atividades de terapia, no próprio ambiente onde ocorria a atividade; momento 2 (M2): imediatamente após o término das atividades de TAA, ainda no ambiente em que foi realizada; e momento 3 (M3): 24 horas decorridas da última avaliação (M2), ou seja, 24h após o final de uma atividade de TAA.

Foram realizadas colheitas de sangue e de saliva, nesta ordem, em cada um dos momentos descritos acima. As amostras de sangue colhidas da jugular no volume de $5 \mathrm{~mL}$ foram centrifugadas por cinco minutos para extração do soro. As amostras de saliva foram obtidas pela colocação da porção absorvente do kit coletor de saliva (kit coletor de saliva - Salivette SARSPET) no assoalho da região vestibular da boca do animal, mantendo-o posicionado com uma pinça por pelo menos um minuto. Posteriormente, os tubos contendo a porção de material absorvente embebido em saliva foram mantidos em uma caixa isotérmica para congelamento e processamento. Todas as amostras de sangue e de saliva foram congeladas a $-80^{\circ} \mathrm{C}$, no máximo dentro de 60 minutos após a colheita, para a posterior mensuração pela técnica de radioimunoensaio e Elisa, respectivamente.

$\mathrm{Na}$ dosagem do cortisol sérico, foi utilizado um kit de radioimunoensaio comercial (kit de cortisol Cout-A-Count - Genesis), e todos os controles, calibradores e desconhecidos foram avaliados em duplicata. Para a dosagem de cortisol salivar, foi utilizado o Kit Salimetrics® (Item no. 1-3002, Single 96 Well Kit), centrifugando-se as amostras a 2000rpm por cinco minutos, seguindo a recomendação do fabricante, obtendo-se $50 \mu \mathrm{L}$ por amostra, para a mensuração em duplicata. As amostras, das quais não se obteve o volume mínimo exigido, foram descartadas. Foram dosadas apenas duas amostras correspondentes ao M0 de cada animal, realizando-se a média aritmética dos dois valores obtidos. Somente em quatro animais obteve-se volume suficiente de saliva correspondentes ao M3.

Foram mensuradas: temperatura retal (TR, em ${ }^{\circ} \mathrm{C}$ ), frequências cardíaca (FC, em bpm) e respiratória ( $\mathrm{FR}$, em $\mathrm{mpm})$, mensuradas por visualização e estetoscopia (Estetoscópio Littman Classic II), e pressão arterial sistólica (PAS, em $\mathrm{mmHg}$ ) pelo método não invasivo utilizando Doppler vascular (Doppler Veterinário DVT 500 - Martec - São Paulo), com adaptação do manguito no membro anterior direito, respeitando-se uma relação de 0,4 entre a largura do manguito e a circunferência do membro. A pressão arterial sistólica foi aferida três vezes em cada momento, sendo considerada a média aritmética das três mensurações.

A avaliação comportamental foi realizada por meio de observação do animal, classificando-o segundo quatro tipos de comportamento: calmo aquele que permanecia com as orelhas e cauda abaixadas; alerta - aquele cuja cauda e orelhas permaneciam apontadas para cima e/ou com um dos pés apontados para frente; agressivo - aquele que apresentasse pelos do dorso eriçados, lábios retraídos caudalmente, orelhas para frente e cuja cauda estivesse abanando lentamente; e com medo não acompanhado de agressividade quando o animal permanecia abaixado, com a cauda entre as pernas e as orelhas caídas. Tal classificação foi baseada nas diferentes formas de expressão social, segundo Houpt (2005). A avaliação comportamental foi conduzida por dois observadores em dois momentos: $1=$ durante as sessões de terapia (comportamento predominante durante a sessão) e 2= em ambiente domiciliar antes de se proceder à coleta de dados para avaliação das características fisiológicas e coleta de sangue e saliva.

Observaram-se, ainda, a ocorrência de doenças, o desenvolvimento de comportamentos estereotipados, a oscilação de peso corporal e a periodicidade de cio durante todo o período de 12 meses. 
Foi realizada a análise estatística dos dados quantitativos, como características vitais, cortisol sérico e salivar. Para tanto, foi realizado o teste de Tukey ou Dunn, de acordo com o teste de normalidade (ZAR, 1998), com significância de $5 \%$, utilizando-se o programa GraphPad InStat. A avaliação comportamental foi avaliada de maneira descritiva.

\section{RESULTADOS}

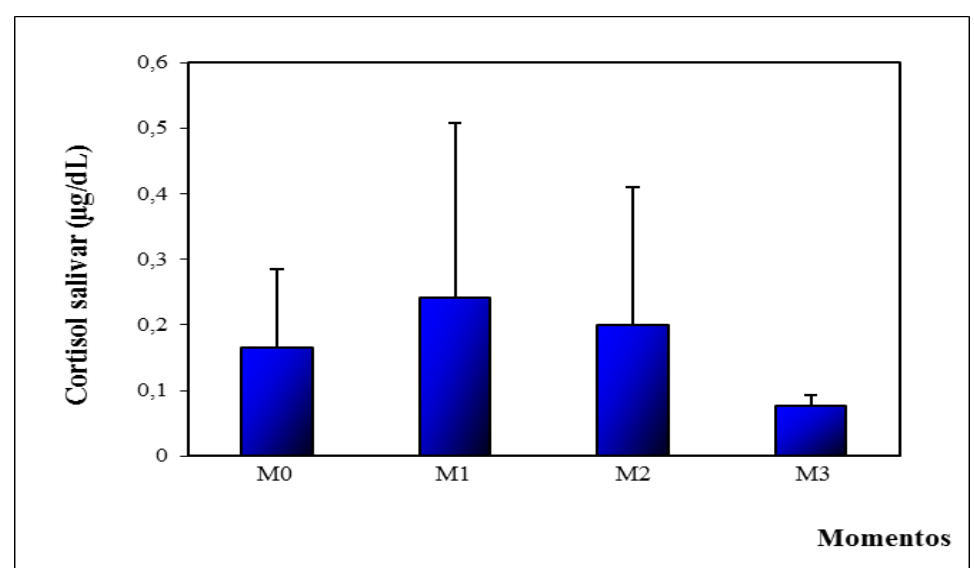

M0 = em repouso; $\mathrm{M} 1=$ imediatamente antes; M2 = imediatamente depois; e M3 = 24h após as atividades de terapia assistida por animais.

Figura 1. Médias e desvios-padrão do cortisol salivar, em $\mu \mathrm{g} / \mathrm{dL}$, de cães da raça Labrador Retriever, em diferentes momentos.

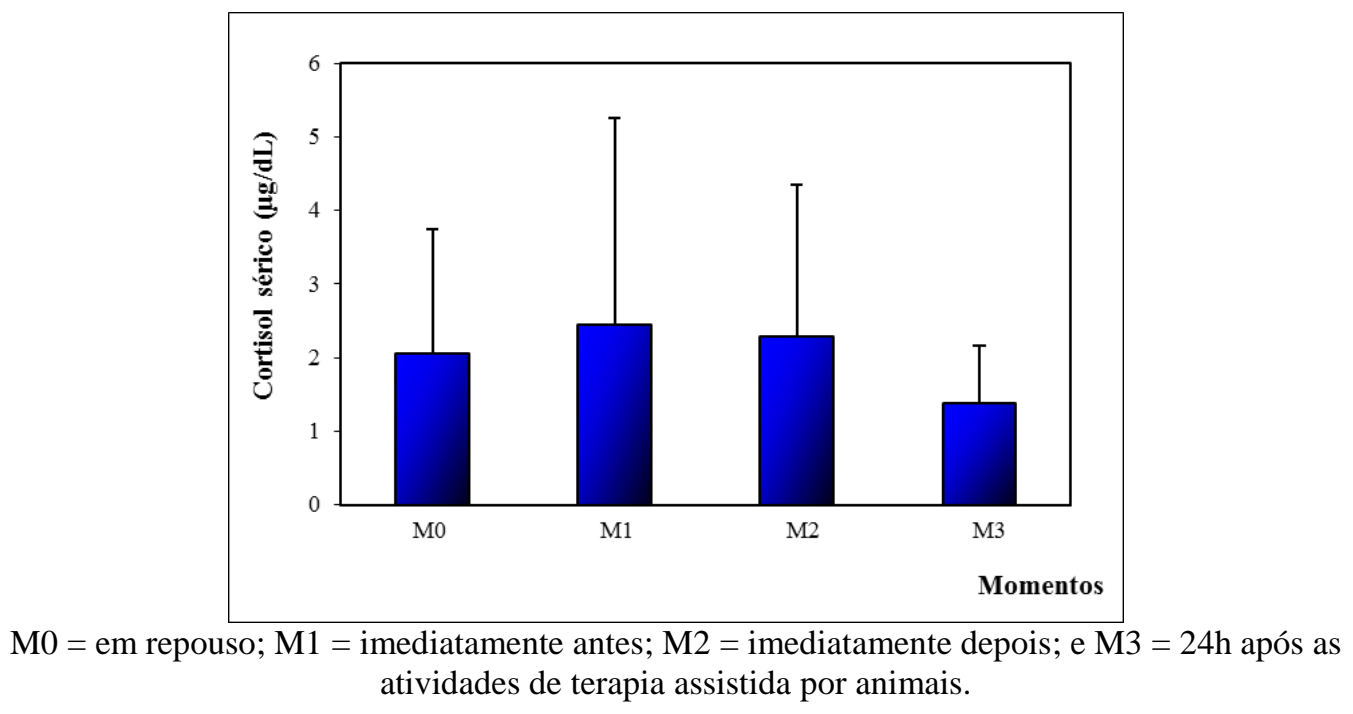

Figura 2. Médias e desvios-padrão do cortisol sérico, em $\mu \mathrm{g} / \mathrm{dL}$, de cães da raça Labrador Retriever, em diferentes momentos. 
A média dos valores obtidos na aferição da frequência cardíaca, frequência respiratória, pressão arterial sistólica e temperatura dos nove animais participantes da TAA, assim como seus respectivos desvios-padrão, está representada nas Fig. 3, 4, 5 e 6 .
Não houve diferença significativa com relação à frequência respiratória $(\mathrm{P}=0,8871)$, pressão arterial sistólica $(\mathrm{P}=0,1908)$ e frequência cardíaca $(\mathrm{P}=0,7780)$ entre os momentos, porém houve diferença significativa com relação à temperatura corpórea dos animais entre os momentos. Esta foi significativamente mais elevada em M1 e M2 do que em M0 ( $\mathrm{P}=0,0088)$.

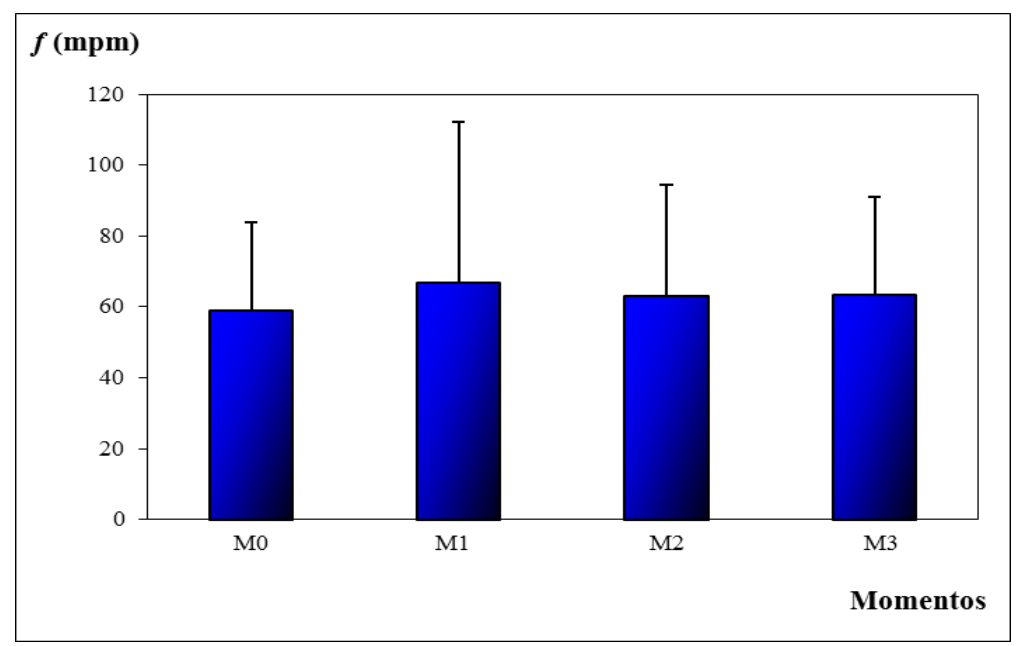

M0 = em repouso; $\mathrm{M} 1=$ imediatamente antes; $\mathrm{M} 2=$ imediatamente depois; e M3 = 24h após as atividades de terapia assistida por animais.

Figura 3. Médias e desvios-padrão da frequência respiratória (FR), em movimentos por minuto (mpm), de cães da raça Labrador Retriever, em diferentes momentos.

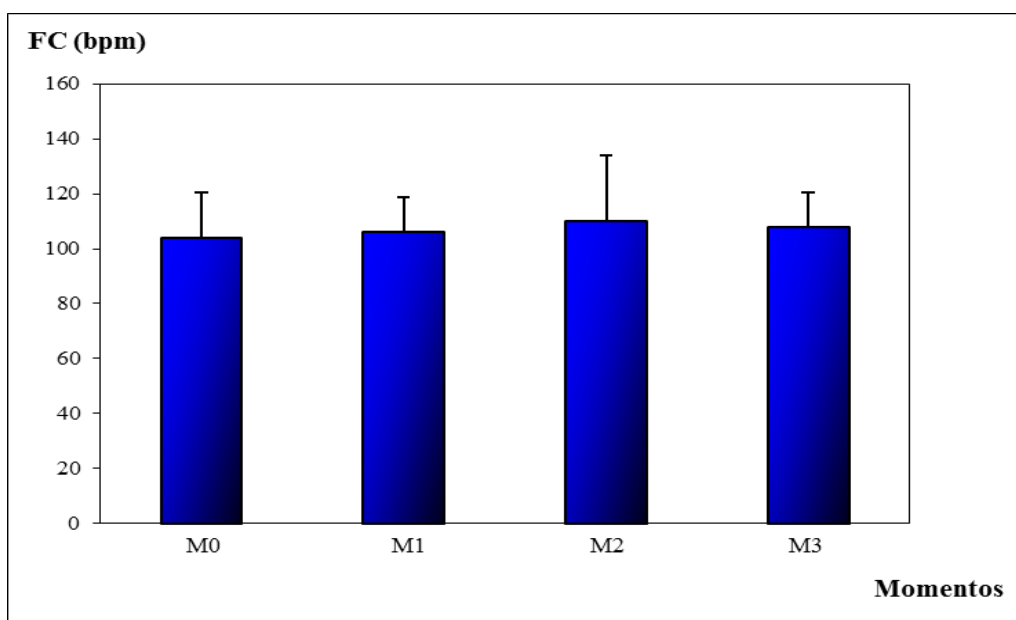

M0 = em repouso; $\mathrm{M} 1=$ imediatamente antes; $\mathrm{M} 2=$ imediatamente depois; e $\mathrm{M} 3=24 \mathrm{~h}$ após as atividades de TAA.

Figura 4. Médias e desvios-padrão da frequência cardíaca (FC), em batimentos por minuto (bpm), de cães da Raça Labrador Retriever, em diferentes momentos. 


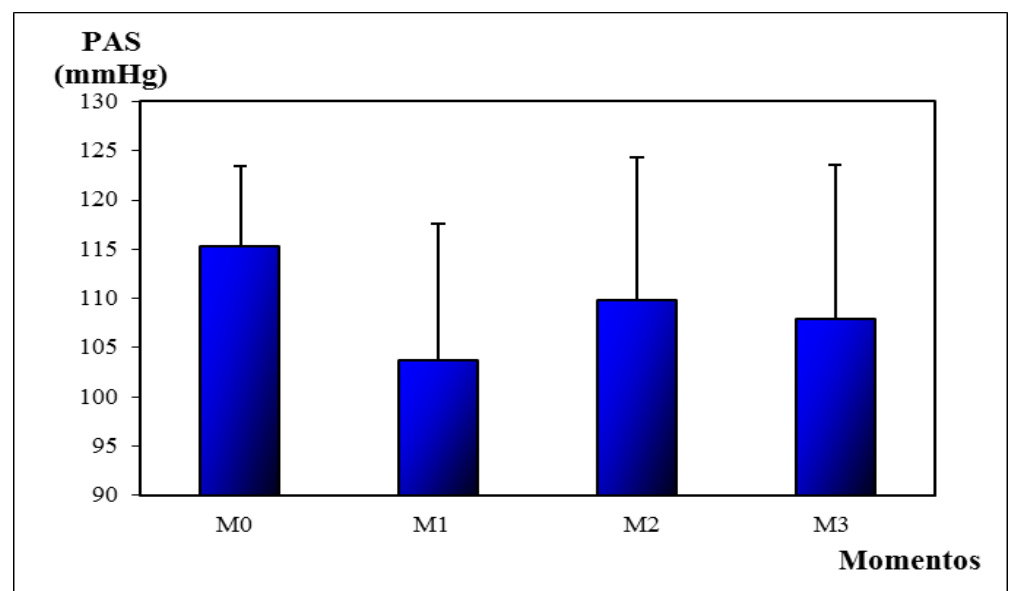

M0 = em repouso; $\mathrm{M} 1=$ imediatamente antes; $\mathrm{M} 2=$ imediatamente depois; e M3 = 24h após as atividades de terapia assistida por animais.

Figura 5. Médias e desvios-padrão da pressão arterial sistólica (PAS), em milímetros de mercúrio $(\mathrm{mmHg})$, de cães da raça Labrador Retriever, em diferentes momentos.

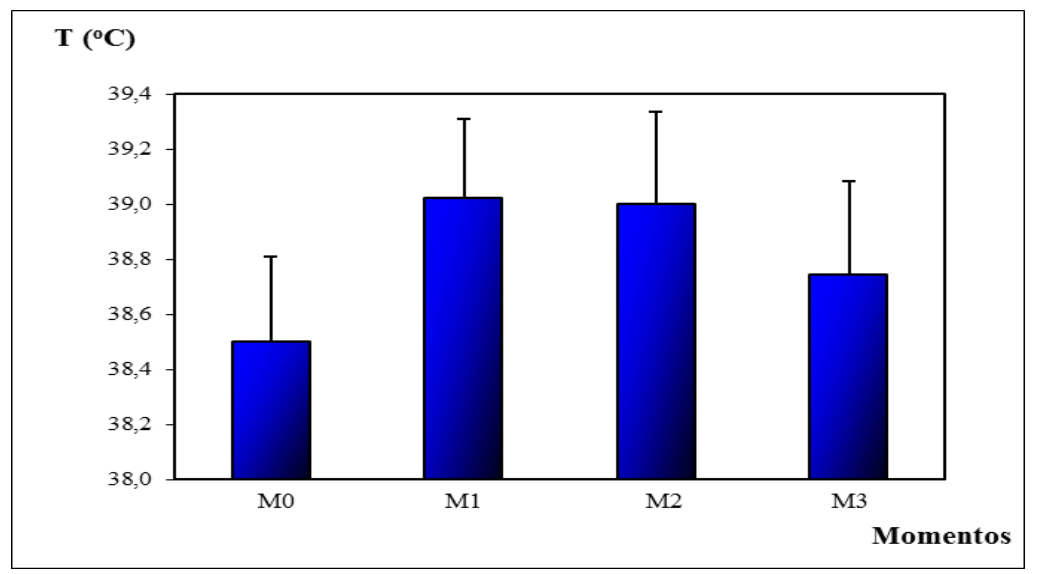

M0 = em repouso; M1 = imediatamente antes; M2 = imediatamente depois; e M3 = 24h após as atividades de terapia assistida por animais.

Figura 6. Médias e desvios-padrão da temperatura retal (TR), em graus Celsius $\left({ }^{\circ} \mathrm{C}\right)$, de cães da raça Labrador Retriever, em diferentes momentos.

A avaliação comportamental não apresentou nenhum resultado negativo, ou seja, nenhum dos cães envolvidos no estudo apresentou comportamento considerado agressivo ou que demonstrasse estar amedrontado. A grande maioria dos animais apresenta-se calmo (5/9) ou em alerta (3/9) em ambiente domiciliar, e em alerta (8/9) durante as atividades de TAA.

Durante o período a que este estudo se refere, um dos cães apresentou episódios de diarreia aguda, diagnosticada como intoxicação alimentar, e outro apresentou dermatite por atopia. Ambas as enfermidades foram tratadas, com boa resposta terapêutica e recuperação rápida. Todas as cadelas não castradas apresentaram cios regulares e com duração normal. Os animais mantiveram os pesos estáveis e não foi constatado o desenvolvimento de comportamentos alterados ou estereotipados, como o descrito por Iannuzzi e Rowan (1991) e Heimlich (2001) durante o período de 12 meses. 


\section{DISCUSSÃO}

A FR atingiu valores considerados acima da normalidade para cães adultos de raça de grande porte, apresentando média e desvio-padrão mais elevados no M1 (Fig. 3). Como não houve diferença significativa entre os momentos, a elevação da frequência respiratória em M1 provavelmente é atribuída à excitação pelo transporte até o local da terapia, bem como à manipulação do animal.

Com relação à $\mathrm{FC}$, não houve muita variação entre as médias dos quatro momentos, apresentando discreta elevação, não significativa, em M2, a qual pode ser decorrente da atividade exercida durante a TAA (Fig. 4).

Os valores de PAS encontraram-se dentro da normalidade, porém com média elevada em M0, no qual se esperavam valores próximos aos demais momentos ou até mais baixos. Tal fato pode estar associado à presença de pessoas estranhas no ambiente familiar do animal, embora essa alteração não tenha sido acompanhada pelas outras características estudadas. Além disso, a PAS também foi aferida no ambiente domiciliar em M3, quando também ocorreu a elevação.

Houve diferença significativa dos valores obtidos da temperatura entre M0 e M1 e entre M0 e M2, em razão, provavelmente, da manipulação e do transporte dos animais até o local da TAA e, até mesmo, pela atividade exercida pelos animais durante $o$ trabalho. Considerando-se o desvio-padrão, observa-se pouca elevação da temperatura em M1 e M2 acima da normalidade. Foi excluída a possibilidade de a elevação da temperatura ser indicativa de alguma alteração sistêmica mórbida, tendo em vista que os animais não desenvolveram sintomas de nenhuma doença e apresentaram temperatura dentro dos valores normais em M3. Essa alteração foi, portanto, atribuída ao clima extremamente quente da cidade, ao exercício e à excitação decorrentes da atividade desenvolvida.

A avaliação comportamental não apresentou nenhum resultado negativo, ou seja, os cães envolvidos no estudo não apresentaram sinais considerados indicadores de agressividade ou de medo. Tal observação confirma o estudo de Heimlich (2001), que demonstrou não haver correlação entre comportamento de estresse ou estereotipados negativos em cães submetidos à TAA. Desse modo, embora de forma subjetiva, pode-se deduzir que a TAA não gera malefícios ao comportamento e ao bem-estar do animal.

Assim, foram mensuradas as concentrações de cortisol salivar e sérico, a fim de se analisar quantitativamente as variações desse hormônio, representativo de estresse, durante os momentos já citados. O cortisol sérico manteve-se mais elevado do que o salivar, em todos os momentos, em maior ou menor grau. Neste estudo, o cortisol salivar representou 5 a $9 \%$ da concentração de cortisol sérico, aproximando-se dos valores citados por Beerda et al. (1996), de 7 a $12 \%$.

No presente trabalho, utilizou-se como padrão de normalidade de cortisol salivar a concentração basal de cães saudáveis, descrita por WengerRiggenbach et al. (2010) como sendo de 0,021$0,091 \mu \mathrm{g} / \mathrm{dL}$ ou $1,54 \pm 0,97 \mathrm{nmol} / \mathrm{L}$ pela técnica de imunoensaio enzimático. Já para a concentração considerada normal de cortisol sérico, foram utilizados os valores de referência propostos por

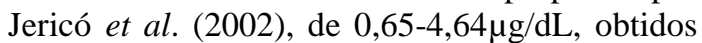
por meio da avaliação de 50 cães e utilizando o método de radioimunoensaio. Sendo assim, considera-se que os valores de cortisol salivar detectados no presente estudo apresentam-se elevados em M0, M1 e M2, 0,1648, 0,2413, $0,1998 \mu \mathrm{g} / \mathrm{dL}$, respectivamente, sendo M1 o mais elevado, $0,23 \mu \mathrm{g} / \mathrm{dL}$. Quanto aos valores séricos do cortisol, pode-se observar que eles se mantiverem dentro da faixa de normalidade quando confrontados com dados de literatura. Contudo, observou-se diferença significativa ao se comparar M1 e M3, o que poderia ser explicado pelo fato de M1 ter sido realizado no local da atividade, logo após o transporte e em ambiente não familiar, enquanto o M3 foi realizado no ambiente familiar do animal, sem a necessidade de transporte e com pessoas do seu convívio diário.

Dessa forma, observa-se que houve elevação das concentrações de cortisol salivar acima da normalidade em determinados momentos (M0, M1 e M2), porém tal fato não ocorreu com relação ao cortisol sérico. Há evidências de que, após um estímulo estressante, existe um aumento das concentrações de cortisol sérico em um curto período, e quatro minutos após essa elevação, ocorre o aumento do cortisol salivar (Kobelt et 
al., 2003). Assim, como a colheita de cortisol salivar foi realizada após a de cortisol sérico, sugere-se que já tenha ocorrido um estímulo estressante pelo procedimento invasivo da coleta de sangue associada à contenção do animal, gerando elevação das concentrações salivares, visto que entre as coletas ocorreu um intervalo de tempo superior ao de quatro minutos. Tal fato, aliado à ausência de comportamento agressivo ou estereotipado por parte dos cães, indica que a elevação do cortisol salivar pode ter sido gerada pela manipulação e contenção dos animais, pela inserção da agulha para a colheita de sangue e pela manutenção dos tubos salivettes em cavidade oral, não sendo, portanto, atribuída à atividade assistida. Sugere-se que, em estudo posterior, a colheita de saliva seja sempre anterior à colheita de sangue e a dos demais parâmetros, a fim de refletir a variação decorrente exclusivamente da atividade, e não da contenção e manipulação.

\section{CONCLUSÕES}

A terapia assistida por animais não parece causar estresse importante aos cães, não interferindo diretamente no bem-estar e na saúde, visto que as alterações dos parâmetros fisiológicos e das concentrações de cortisol salivar parecem estar relacionadas à contenção e manipulação do animal para a obtenção das amostras, e também pelo fato de não ter sido observado comportamento de estresse negativo. Dessa forma, a TAA deve ser enfatizada, uma vez que provoca benefícios aos humanos e não prejudica o animal.

\section{AGRADECIMENTOS}

À FAPESP, pela bolsa-concessão de iniciação científica; aos professores Guilherme de Paula Nogueira e Sandra Helena Penha de Oliveira, pela disponibilização dos laboratórios de endocrinologia e de fisiologia, respectivamente, para as dosagens laboratoriais de cortisol.

\section{REFERÊNCIAS}

BEERDA, B.; SCHILDER, M.B.; JANSSEN, N.S.; MOL, J.A. The use of saliva cortisol, urinary corisol, and catecholamine measurements for a noninvasive assessment of stress responses in dogs. Horm. Behav., v.30, p.272-279, 1996.
BEERDA, B.; SCHILDER, M.B.; VAN HOOFF, J.A. et al. Behavioural, saliva cortisol and heart rate responses to different types of stimuli in dogs. Appl. Anim. Behav. Sci., v.58, p.365-381, 1998.

BEERDA, B.; SCHILDER, M.B.; VAN HOOFF, J.A. et al. Chronic stress in dogs subjected to social and spatial restriction: 2 . Hormonal and immunological responses. Physiol. Behav., v.66, p.243-254, 1999.

DOTTI, J. Terapia e animais. São Paulo: Noética, 2005. 294p.

FRANK, D. et al. Placebo-controlled doubléblind clomipramine trial for the treatment of anxiety or fear in beagles during ground transport. Can. Vet. J., v.47, p.1102-1108, 2006.

HAUBENHOFER, D.K.; KIRCHENGAST, S. Physiological arousal for companion dogs working with their owners in animal-assisted activities and animal-assisted therapy. J. Appl. Anim. Welf. Sci., v.9, p.165-172, 2006.

HEIMLICH, K. Animal-assisted therapy and the severely disabled child: A quantitative study. $J$. Rehabilitation, v.67, p.48-54, 2001.

HOUPT, K.A. Communication. In:__Domestic animal behavior. 4.ed. Ames: Blackwell Publishing, 2005. 513p.

IANNUZZI, D.; ROWAN, A.N. Ethical Issues in Animal-Assisted Therapy Programs. Anthrozoos, v.4, p.154-163, 1991.

JERICÓ, M.M.; DE MENDONÇA, B.B.; OTSUKA, M. et al. Non-radiometric immunoassays [Fluoproimunoassay (FIA) and fluorometric enzyme immunoassay (FEIA)] with radioimmunoassay (RIA) for evaluation of adrenal function in normal and hypercortisolemic dogs. Cienc. Rural. v.32, p.259-262, 2002.

KOBELT, A.J.; HEMSWORTH, P.H.; BARNETT, J.L. et al. Sources of sampling variation in saliva cortisol in dogs. Res. Vet. Sci., v.75, p.157-161, 2003.

OLIVA, V.N.L.S.; JUNIOR, A.B.S.; CARVALHO, E.A.G. et al. Experiências clínicas do projeto cão-cidadão-unesp no hospital neurológico Ritinha Prates - Araçatuba - SP. In: CONGRESSO DE EXTENSÃO UNIVERSITÁRIA DA UNESP, 4., 2007, Águas de Lindóia. Anais...São Pauo: [s/n], 2007. (Resumo). 
OLIVA, V.N.L.S. Terapia Assistida por Animais. In: COSTA NETO, E.M.; ALVES, R.R.N. Zooterapia - os animais na medicina popular brasileira, 1.ed. Recife: NUPEEA, 2010. p.127-140.

QUEYRAS, A.; CAROSI, M. Non-invasive techniques for analysing hormonal inicators of stress. Ann 1st Super Sanità. v.40, p.211-221, 2004.

UDELL, M.A.R.; WYNNE, C.D.L. A review of domestic dogs' (Canis familiaris) human-like behaviors: or why behavior analysts should stop worrying and love their dogs. J. Experim. Anal. Behav., v.89, p.247- 261, 2008.
WENGER-RIGGENBACH, B. citar até o 30 autor et al. Salivary cortisol concentrations in healthy dogs and dogs with. J. Vet. Int. Med., v.24, p.551-556, 2010.

ZAR, J.H. Biostatistical Analysis. 4.ed. New Jersey: Prentice Hall, 1998. 663 p. 